\title{
EARLY ALGEBRAIC THINKING: EXPLORING REPEATING PATTERNS WITH KAHOOT. A STUDY WITH PRE-SERVICE PRIMARY TEACHERS AND PRE-SERVICE KINDERGARTEN TEACHERS
}

\author{
N. Santos, P. Afonso, D. Alveirinho \\ Centro de Investigação em Património, Educação e Cultura (CIPEC), Instituto Politécnico de \\ Castelo Branco (PORTUGAL)
}

\begin{abstract}
The aim of the study was to know the level of development of algebraic thinking in Higher Education students. During the investigation, we wanted to measure the success rate in the size of the next generalization and the dimension of distant generalization and measure the degree of difficulty in the various proposed patterns. In the context of the training of future primary teachers and childhood educators, an activity was developed in the context of the curricular unit of mathematical recreation with 15 students. The theme of algebraic thinking assumes current relevance because according to [1], it has become a cross-cutting theme of the curriculum. In order to know the level of algebraic thinking, 4 tasks with repetition patterns were proposed from elements of the manipulable material: pattern blocks. The tasks were presented through Kahoot, an applet that allows, according to [2] and [3] to increase motivation, to improve concentration, to promote reasoning, to allow collaborative work, to reverse roles between student and teacher, use ICT in the classroom and evaluate in real time. Repeat patterns were proposed from the simplest to the most complex (ABAB, ABBABB, ABCABC, $A B C C A B C C$ ). For this proposal, we have considered Vitz and Todd [4], who present a model of repetition pattern classification. In each task we proposed 2 questions that involved near generalization (10th term and 15th term) and 2 distant generalization questions (35th term and 100th term). In methodological terms the teacher projected each pattern and its questions on the projection screen so that all students could visualize, and each student responded individually using their mobile phone, tablet, or laptop computer. For each question, the students had a resolution time of 90 seconds. In none of the questions has the student's resolutions been exhausted. The results allowed to verify that of the 16 questions proposed, there was a percentage of correctness in the $71,67 \%$ (average of the questions). Regarding the near generalization, we obtained a percentage of success in the order of $70 \%$. On the other hand, in relation to the distant generalization, we obtained a percentage of success in the order of $73,33 \%$. We also observed that students showed greater ease in the ABBABB pattern, with a success rate of $80 \%$ and greater difficulty in $A B A B$ with a success rate of $56.67 \%$. Regarding the $A B C A B C$ pattern, we obtained a success rate of $75 \%$ and a success rate for the ABCCABCC pattern.
\end{abstract}

Keywords: Algebraic Thinking, Kahoot, generalization, ICT, Repeating patterns.

\section{INTRODUCTION}

Algebra plays a key role in learning mathematics in the early years. As [5] point out, although algebra is associated with solving equations, inequalities, dealing with unknown unknowns, moments in which mathematics becomes more complex for students, algebra goes a lot beyond this definition. Indeed, such authors as [6] considers that the need to learn arithmetic is more acceptable than developing a learning algebraic thought in the early years. However, the separation of arithmetic and algebra into separate compartments in the early years with a greater focus on arithmetic and subsequent study cycles a greater focus on algebra makes learning mathematics more difficult [7]. Algebraic thinking, in the early years, represents an extension of arithmetic and ease in calculus to the consideration of the underlying mathematical principles [8]. [9] considers that in the transition from arithmetic to algebra a relevant approach may be through the observation of patterns, their description and later by their generalization. It should be noted that the focus of algebraic thinking is exactly the generalization [10]. [11] even go so far as to reiterate that a class, which does not give students the opportunity to generalize, cannot effectively be considered a mathematics class. Patterns, being a cross-cutting theme within mathematics itself, may represent an interesting way of making the transition between arithmetic and algebra. After all, children from an early age have already informally developed contact 
with these same patterns, whether through poems, songs, or even in the environment that surrounds them, in their own daily lives [5]. Considering the theoretical framework presented, we considered relevant to address the patterns of repetition with students in the initial training of a primary school teachers and childhood educators. In the future, these professionals will contact children from an age group ranging from 0 to 10 years old. Besides being fundamental to make the transition from arithmetic to algebra in a coherent way, these two mathematical themes must be worked in an integrated way. In this approach, we have chosen to work only on repetition patterns. The primordial notion of a pattern involves change or repetition [1]. This notion of repetition is well demonstrated in [12] and [4] noting that in a repeat pattern there is a unit that repeats cyclically. [4] refers to the work of [13] and [14], in which the authors propose models of ordering repetition patterns from the simplest to the most complex. In this work, we have considered the proposal of Vitz and Todd, in order to present the tasks to students from the simplest to the most complex repetition pattern. In this investigation, four tasks involving the following repetition patterns were proposed: $A B A B, A B C A B C, A B B A B B$, $A B B C C A B B C C$. Each task involved four issues. Two of the questions involved near generalization, in which students had to identify terms close to the sequence, namely the $10^{\text {th }}$ and $15^{\text {th }}$ terms and two questions involving distant generalization, to identify the $35^{\text {th }}$ and $100^{\text {th }}$ terms of the sequence. In order to propose these tasks in an interactive way, we used Kahoot, an application that allows the teacher to make his classes much more interactive. [15] points out that game-based learning applications allow for improved problem-solving skills and understanding of certain mathematical concepts. Mobile learning proposes a new paradigm for school and teachers, challenging innovation in teaching and learning practices. After all, mobile technologies can expand and provide educational opportunities for students in diverse contexts [16].

\section{METHODOLOGY}

At an early stage, we chose to build the research tasks. As we intended to make a diagnosis regarding the level of algebraic thinking of students in the first year of a training course for primary teachers and childhood educators, we chose to construct tasks with pictorial standards, from elements of the manipulative material - Pattern Blocks. This material allows to promote creativity, thus being an excellent working tool that allows cross-cutting, a huge variety of mathematical concepts of the various themes that make up the curricular programs this area of knowledge [17]. As we mentioned earlier, we follow the work of Vitz and Todd, who identifies an order of patterns from the most to the most complex. Thus, the first standard built was the ABAB pattern. In Figure 1 we present the proposed pattern:

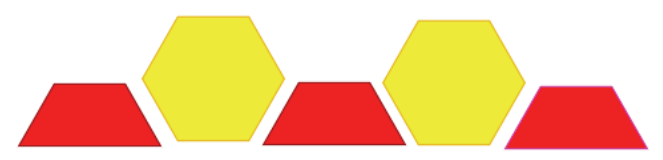

Figure 1. ABAB Pattern proposed in the $1^{\text {st }}$ research task.

In the second task, we define the $A B C A B C$ repetition pattern using the elements of the pattern blocks, namely the square, the rhombus and the hexagon.

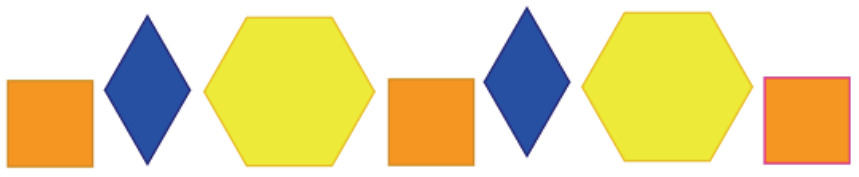

Figure 2. $A B C A B C$ Pattern proposed in the $2^{\text {nd }}$ research task.

In turn, we define the ABBABB repetition pattern through the square and the trapezoid. In Figure 3 we present the sequence that allowed to construct the $3^{\text {rd }}$ task through the elements of the material Pattern Blocks.

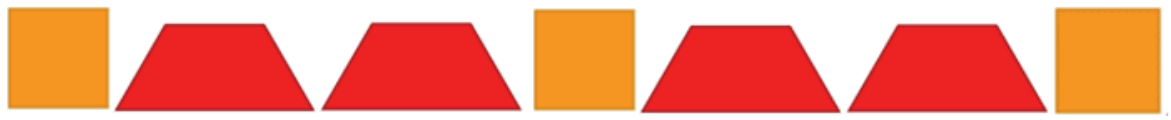

Figure 3. ABBABB Pattern proposed in the $3^{\text {rd }}$ research task. 
Finally, we define the $A B C C A B C C$ repetition pattern through the rhombus, the triangle and the square. In Figure 4 we present the sequence that allowed us to construct the $4^{\text {th }}$ task

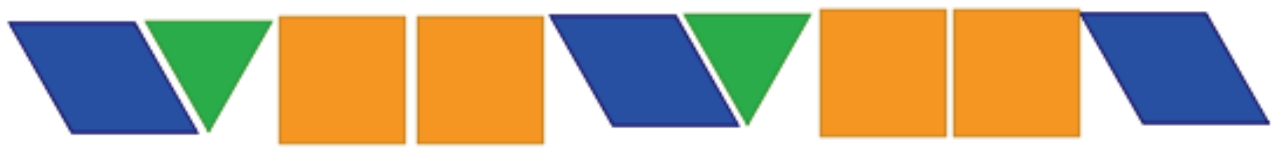

Figure 4. ABCCABCC Pattern proposed in the $4^{\text {th }}$ research task.

As we mentioned in the introduction to this article, after outlining the proposed repetition patterns, we intend to maintain the homogeneity of the questions to be asked for each task, proposing two questions of near generalization $\left(10^{\text {th }}\right.$ term, $15^{\text {th }}$ term $)$ and two questions of distant generalization $\left(45^{\text {th }}\right.$ term and $100^{\text {th }}$ term). In each question we said that the sequence maintained regularity. Each task was built in the Kahoot. During the tasks, the teacher designed the different tasks and the students answered through their laptops, tablets and smartphones. In this study, we opted for the quiz mode, where each question arises with four response options, through a multiple-choice system. In each question, the students had a resolution time of two minutes. It is important to note that in no question did the students exceed the defined time limit. We have selected Kahoot because this application allows the teacher to approach any content, from any disciplinary area in an interactive way. In addition, it allows a real-time evaluation of the training. In our case, we focused on the area of mathematics and more specifically on the theme of algebraic thinking. This application allows you to build surveys, questionnaires, quizzes. In this study itself, we used the quiz modality. In this option, the questions are based on multiple choice answers, in this way, the students and the teacher build and share contents and knowledge [18]. Kahoot has many potentialities as we refer to throughout the text, namely increase motivation in the teaching and learning process, improve concentration, promote reasoning, allow collaborative work, use ICT in the classroom, reverse the role of the student and the teacher and still evaluate in real time [2] [3]. As an example, we present in Figure 5 the projection of the first question of near generalization, with the intention of identifying the $10^{\text {th }}$ figure of the sequence for the $A B C A B C$ repetition pattern.

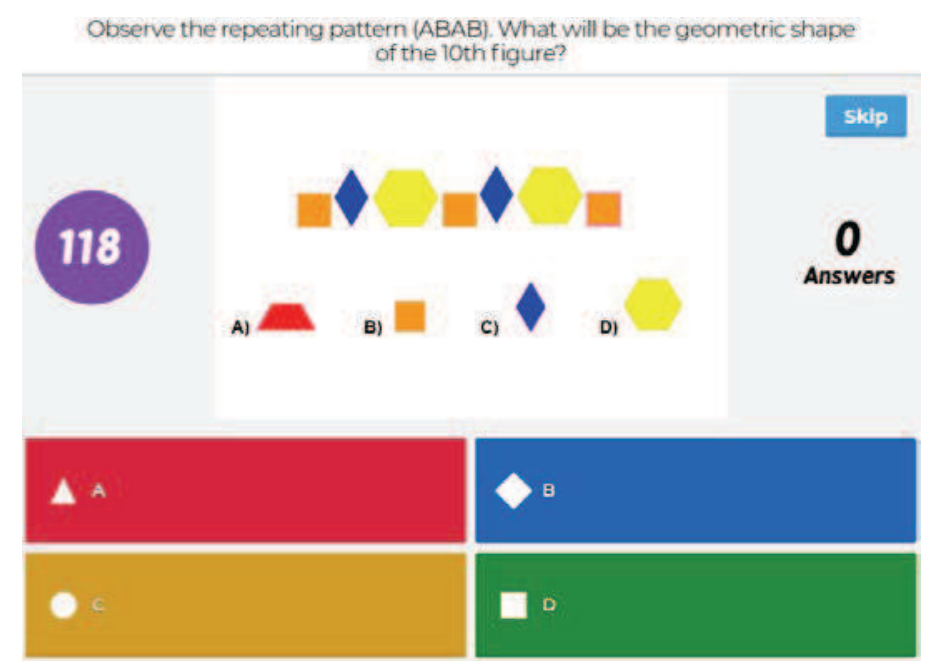

Figure 3. Near generalization question regarding the second task referring to the $A B C A B C$ pattern presented by Kahoot.

When students finished answering the 16 questions, they had the opportunity to evaluate the quiz, whether they had fun doing the proposed tasks, how they felt during the challenge, and whether they would recommend the quiz to other students. It should be noted that this research was based on identifying the level of algebraic thinking of students in a training course for primary school teachers and early childhood educators. This activity was carried out in a context of mathematical recreation with 15 students, in a session of 90 minutes. 


\section{RESULTS}

Considering the results generated by the Kahoot report, we did an analysis question by issue, task by task, comparison of the near generalization and the distant generalization. Table 1 shows the results obtained by the students, through the average among the various parameters under evaluation.

Table 1. Synthesis of the results obtained in the study regarding the success rate.

\begin{tabular}{|c|c|c|c|c|c|c|c|c|c|c|c|c|c|c|c|c|}
\hline & \multicolumn{16}{|c|}{ Repeating Pattern } \\
\hline Repeating & \multicolumn{4}{|c|}{ ABAB } & \multicolumn{4}{|c|}{ ABCABC } & \multicolumn{4}{|c|}{ ABBABB } & \multicolumn{4}{|c|}{ АВССАВCС } \\
\hline Generalization & \multicolumn{2}{|c|}{ NG } & \multicolumn{2}{|r|}{ DG } & \multicolumn{2}{|c|}{ NG } & \multicolumn{2}{|c|}{ DG } & \multicolumn{2}{|c|}{ NG } & \multicolumn{2}{|c|}{ DG } & \multicolumn{2}{|r|}{ NG } & \multicolumn{2}{|c|}{ DG } \\
\hline Questions & Q1 & Q2 & Q3 & Q4 & Q1 & Q2 & Q3 & Q4 & Q1 & Q2 & Q3 & Q4 & Q1 & Q2 & Q3 & Q4 \\
\hline $\begin{array}{c}\text { Average per } \\
\text { question }\end{array}$ & $40 \%$ & $66,67 \%$ & $60 \%$ & $60 \%$ & $73,33 \%$ & $86,67 \%$ & $93,33 \%$ & $46,67 \%$ & $66,67 \%$ & $100 \%$ & $80 \%$ & $73,33 \%$ & $60 \%$ & $66,67 \%$ & $86,67 \%$ & $86,67 \%$ \\
\hline $\begin{array}{l}\text { Average per } \\
\text { generalization }\end{array}$ & & $35 \%$ & & $60 \%$ & 80 & & 70 & & 83,3 & & & $65 \%$ & & $3,335 \%$ & & $7 \%$ \\
\hline $\begin{array}{l}\text { Average per } \\
\text { pattern }\end{array}$ & \multicolumn{4}{|c|}{$56,668 \%$} & \multicolumn{4}{|c|}{$80 \%$} & \multicolumn{4}{|c|}{$80 \%$} & \multicolumn{4}{|c|}{$86,67 \%$} \\
\hline $\begin{array}{c}\text { Average per } \\
\text { NG }\end{array}$ & \multicolumn{16}{|c|}{$70 \%$} \\
\hline $\begin{array}{c}\text { Average per } \\
\text { DG }\end{array}$ & \multicolumn{16}{|c|}{$73,334 \%$} \\
\hline
\end{tabular}

Considering the data in table 1 , we can say that, with respect to the near generalization (NG), a success rate of around $70 \%$ was obtained. In turn, relative to distant generalization (DG), the success rate was in the order of $73.33 \%$. These results contradict several recent studies, such as [19] and [20], which showed better results at the level of near generalization. Students showed greater difficulty with $A B A B$, with a success rate of $56.668 \%$. Contrary to what we would expect, before beginning this study, students showed greater ease in the ABCCABCC pattern. In the remaining patterns the results were as follows: $80 \%$ for the ABCABC pattern and also $80 \%$ for the ABBABB pattern. These results contradict the proposal of [13] and [14] indicate the order of complexity of the patterns. In table 2 we present a table generated by the Kahoot report that allows to analyse the overall performance of the students in the quiz.

Table 2. Students ' performance regarding Kahoot's questions

\begin{tabular}{|c|c|}
\hline \multicolumn{2}{|c|}{ Overall Performance } \\
\hline Total correct answers (\%) & $71,67 \%$ \\
\hline Total incorrect answers (\%) & $28,33 \%$ \\
\hline
\end{tabular}

Table 2 shows the overall results of the students in relation to their performance. In our view, the students demonstrated a very satisfactory level regarding the success rate of this quiz. The success rate indicated $71.67 \%$, in turn the failure rate was in the order of $28.33 \%$. As mentioned earlier, throughout the methodology, the students evaluated the quiz on several parameters, namely whether they had fun doing the quiz, whether they had learned something new, whether they recommended the quiz to other students, and how they felt after the quiz. completion of the proposed tasks. The table 3 generated in the report allows evidence of student feedback. 
Table 3. Students'feedback about the quiz

\begin{tabular}{|l|c|c|c|}
\hline \multicolumn{3}{|c|}{ Feedback } \\
\hline How fun was it? (out of 5) & 4 out of 5 \\
\hline Did you learn something? & $100 \%$ Yes & $0 \%$ No & \\
\hline Do you recommend it? & $100 \%$ Yes & $0 \%$ No & \\
\hline How do you feel? & 0 & & 0 \\
& $90 \%$ Positive & $10 \%$ Neutral & $0,00 \%$ Negative \\
\hline
\end{tabular}

The results allowed us to verify that the students considered the activity to be fun, having assigned the average of the different perspectives a 4 on a scale between 0 and 5 . In addition to having fun, all the students considered that they learned something new with the tasks proposed. All recommended the quiz to other students, with $90 \%$ feeling positive after the end of the quiz and $10 \%$ felt neutral after the end of the activities.

\section{CONCLUSIONS}

Today we live in an era of profound social change. School and education, as fundamental pillars, cannot ignore these changes. Technologies take a unique place in the life of a new generation of students. Knowledge is a click away and the teacher as an actor and promoter of knowledge must follow the evolution of the times. The young people who are in the classroom today belong to the generation of digital natives. Given the above, the teacher will have to promote interactive classes that promote new skills that prepare students for the requirements of the $21^{\text {st }}$ century. This interactivity has particular importance in the discipline of mathematics, a discipline with high rates of failure. In Portugal, a group was recently formed to study the causes of failure to discipline. We believe that tools such as Kahoot can promote more positive attitudes toward mathematics. This statement is clearly shown in table 3, where a large part of the students $(90 \%)$ consider themselves satisfactorily after the quiz. In addition, all students recommend the quiz to other students, considering that they have learned something new. The students had more difficulties in questions that involve near generalization. This study also allowed us to verify that they had more difficulty in the ABAB pattern and greater ease in the $A B C C A B C C$ pattern. These results contradict our expectations before the study and some studies referred to earlier as [19] and [20], which indicate better results at the level of the near generalization and $A B A B$ pattern with worse results. In an upcoming study it would be important in addition to analyzing the success rate of students, also analyze the strategies used by each student to justify their decision making.

\section{REFERENCES}

[1] I. Vale e T. Pimentel, Padrões em Matemática: Uma proposta didática no âmbito do novo programa para o Ensino Básico, Lisboa: Texto Editores, 2011.

[2] A. Wang, "The wear out effect of a game-based student response system," Computers in Education, $\mathrm{n}^{\circ}$ 82, pp. 217-227, 2015.

[3] D. Guimarães, "Kahoot: quizzes, debates e sondagens," em Apps para dispositivos móveis: manual para professores, formadores e bibliotecários, Lisboa, ME, 2015, pp. 203-224.

[4] J. Threlfall, "Repeating Patterns in the Early Primary Years," em Pattern in the Teaching and Learning of Mathematics, London, Cassel, 1999, pp. 18-30.

[5] T. Pimentel, I. Vale, F. Freire, D. Alvarenga e A. Fão, Matemática nos primeiros anos: Tarefas e desafios para a sala de aula, Lisboa: Texto Editores , 2010.

[6] Z. Usiskin, "Why is Algebra Important to Learn?," American Educator , n 19, pp. 30-37, 1995.

[7] C. Kieran, "Algebraic thinking in the early grades: What is it?," The Mathematics Educator (Singapore), vol. 8, n 1, pp. 139-151, 2004. 
[8] J. Cai e J. Moyer, "Developing Algebraic Thinking in Earlier Grades: Some Insights from International Comparative Studies," em Algebra and Algebraic Thinking in School Mathematics - Seventieth Studies, C. Greenes e R. Rubenstein, Edits., Reston, NCTM, 2008, pp. 169-180.

[9] J. Mason, "Expressing Generality and Roots of Algebra," em Approaches to Algebra: Perspectives for research and teaching, N. Bednarz, C. Kieran e L. Lee, Edits., Dordrecht, Kluwer Academic, 1996, pp. 65-86.

[10] A. Canavarro, "O pensamento algébrico na aprendizagem da Matemática nos primeiros anos," Quadrante, vol. XVI, n² 2, pp. 81-118, 2007.

[11] J. Mason e S. Johnston-Wilder, Designing and Using Mathematical Tasks, St. Albans: Tarquin/The Open University, 2006.

[12] J. Ponte, N. Branco e A. Matos, "Álgebra no Ensino Básico," DGIDC, Lisboa, 2009.

[13] P. Vitz e T. Todd, "A coded element model of the perceptual processing of sequential stimuli," Psychological Review, vol. 76, n 5, pp. 433-449, 1969.

[14] P. Vitz e T. Todd, "A model of learning for simple repeating binary patterns," Journal of Experimental Psychology, vol. 75, nº 1, pp. 108-117, 1967.

[15] J. Carr, "Does Math Achievement "h'APP'en" when iPads and Game-Based Learning Are Incorporated into Fifth-Grade Mathematics Instruction?," Journal of Information Technology Education: Research, vol. 11, nº 1, pp. 269-286, 2012.

[16] UNESCO, "Policy guidelines for mobile learning," UNESCO, Paris, 2013.

[17] P. Afonso, A. Conceição, F. Costa, J. Filipe e M. Serrasqueiro, Aprender matemáticas nos primeiros anos: algumas propostas de tarefas, Castelo Branco: IPCB, 2008.

[18] C. Melo, J. Souza, K. Freitas e F. Cardoso, "Utilização do software Kahoot no ensino da Matemática: um relato de experiência," em Anais do III COLBEDUCA - Colóquio LusoBrasileiro de Educação, Braga, 2017.

[19] J. Carrilho, "Análise às tomadas de decisão dos alunos do $2^{\circ}$ ano do $1^{\circ}$ Ciclo do Ensino Básico na resolução de tarefas que envolvem padrões de repetição," IPCB, Castelo Branco, 2018.

[20] N. Santos, "Influência da tecnologia no desenvolvimento do pensamento algébrico: Um estudo no $1^{\circ} \mathrm{CEB}, "$ IPCB, Castelo Branco, 2016. 